\title{
ANALISIS PENDAPATAN USAHATANI JAMBU BIJI VARIETAS GETAS MERAH DI DESA PANYINGKIRAN, KECAMATAN PANYINGKIRAN, KABUPATEN MAJALENGKA
}

\section{ANAL YSIS OF INCOME FARMING OF RED GETAS GUAVA VARIETIES IN PANYINGKIRAN VILLAGE, PANYINGKIRAN SUB-DISTRICT, MAJALENGKA DISTRICT}

\author{
Nadyla Rizka Nur Amelia ${ }^{1^{*}}$, Dini Rochdiani ${ }^{1}$, Bobby Rachmat Saefudin ${ }^{2}$ \\ ${ }^{1}$ Prodi Agribisnis, Fakultas Pertanian Universitas Padjajaran \\ ${ }^{2}$ Prodi Agribisnis, Fakultas Pertanian Ma'soem University \\ Email: nadylarizkanuramelia@gmail.com \\ (Diterima 06-05-2020; Disetujui 16-06-2020)
}

\begin{abstract}
ABSTRAK
Salah satu produk hortikultura yang banyak dikonsumsi oleh masyarakat ialah buah jambu biji varietas getas merah. Tujuan penelitian ini adalah mengetahui pendapatan usahatani dan imbangan penerimaan dan biaya yang terjadi pada usahatani jambu biji varietas getas merah petani SOP dan Non SOP. Penelitian ini dilakukan di Desa Panyingkiran, Kecamatan Panyingkiran, Kabupaten Majalengka yang merupakan sentra produksi jambu biji varietas getas merah di Jawa Barat. Desain penelitian ini adalah kualitatif dengan metode survei. Sampel penelitian ini yaitu 3 orang petani yang menggunakan SOP yang diperoleh melalui sensus dan 50 orang petani Non SOP yang diperoleh melalui rumus slovin dengan metode acak sederhana. Strata yang digunakan dalam penelitian ini berdasarkan luas lahan tanaman jambu biji varietas getas merah. Hasil penelitian menunjukkan bahwa: (1) Pendapatan rata-rata usahatani petani jambu biji varietas getas merah di Desa Panyingkiran, Kecamatan Panyingkiran, Kabupaten Majalengka secara umum menguntungkan. Petani dengan rata-rata pendapatan atas biaya tunai tertinggi diperoleh oleh petani SOP yang berlahan garapan sempit yaitu Rp 209.805.922/ha/tahun, dan petani Non SOP berlahan garapan sedang yaitu Rp 100.858.775/ha/tahun. Sedangkan rata-rata pendapatan atas biaya total tertinggi diperoleh oleh petani SOP yang berlahan garapan luas yaitu Rp 165.429.758/ha/tahun, dan petani Non SOP berlahan garapan sedang yaitu Rp 64.339.333/ha/tahun, dan (2) Nilai R/C atas biaya tunai tertinggi terdapat pada petani SOP berlahan garapan luas $(\mathrm{R} / \mathrm{C}=17,1)$, dan pada petani Non SOP berlahan garapan sedang $(\mathrm{R} / \mathrm{C}=4,6)$. Sedangkan, nilai $\mathrm{R} / \mathrm{C}$ atas biaya total tertinggi terdapat pada petani SOP berlahan garapan luas $(\mathrm{R} / \mathrm{C}=9,9)$ dan pada petani Non SOP terdapat pada petani berlahan garapan sedang $(\mathrm{R} / \mathrm{C}=2,0)$.
\end{abstract}

Kata kunci: Usahatani, Jambu Biji varietas Getas Merah, Pendapatan

\begin{abstract}
One of the horticultural products widely consumed by the public is guava fruit. West Java is a province with the second largest number of red getas guava varieties produced in Indonesia. The purpose of this study is to know the costs of production, revenue, income, and ratio of revenue $(R)$ and cost $(C)$ that happened on red getas guava varieties in Desa Panyingkiran, Kecamatan Panyingkiran, Kabupaten Majalengka. This research was conducted in Desa Panyingkiran, Kecamatan Panyingkiran, Kabupaten Majalengka which is the center of production of red getas guava varieties in West Java. The design of this research is qualitative survey method. The sample of this research is 3 SOP farmers obtained through census and 50 Non SOP farmers obtained through the Slovin formula with a simple random method. The strata used in this study were based on the area of red getas guava varieties. The results showed that: (1) The results showed the farmer with the highest cash cost income is obtained by SOP farmer who use narrow land area it is $R p$ 209.805.922/Ha/year and Non SOP Farmer with medium land area it is $R p$
\end{abstract}


100.858.775/Ha/year. While, the farmers with the highest total cost income is obtained by SOP farmers who use large land area it is Rp 165.429.758/Ha/year and Non SOP Farmers with medium land area it is $R p$ 64.39.333/Halyear, and (2) The highest $R / C$ of cash cost farmer is obtained by $S O P$ farmer with large land area $(R / C=17,1)$ and on Non SOP farmer with medium land area $(R / C=4,6)$. While, the highest $R / C$ of total cost farmer is obtained by SOP farmer with large land area $(R / C=9,9)$ and on Non SOP farmer with medium land area $(R / C=2,0)$.

Keywords: Farming, Red Getas Guava Varieties, Income

\section{PENDAHULUAN}

Tanaman buah merupakan produk hortikultura yang sangat bermanfaat bagi tubuh manusia. Salah satu buah yang paling banyak dikonsumsi masyarakat adalah jambu biji. Kabupaten Majalengka merupakan sentra produksi jambu biji terbesar di Jawa Barat dengan total produksi 52.684 kuintal (Badan Pusat Statistik Provinsi Jawa Barat, 2019). Kecamatan Panyingkiran merupakan penghasil jambu biji terbesar di Kabupaten Majalengka dengan jumlah produksi 2569,50 ton (Badan Pusat Statistik Kabupaten Majalengka, 2019).

Desa Panyingkiran ialah salah satu desa sentra produksi jambu biji dengan varietas getas merah. Menurut Buku Pertanian Desa Panyingkiran (2019), jumlah produksi paling rendah terjadi pada tahun 2018 yaitu 457 ton. Banyak faktor yang mempengaruhi penurunan produksi diantaranya penggunaan faktor produksi yang kurang efisien, petani belum terampil, dan belum secara keseluruhan menerapkan Standar Operasional Prosedur (SOP). Dalam SOP ini, petani harus melakukan usahatani dengan pemeliharaan secara intensif sehingga menghasilkan produksi jambu biji varietas getas merah yang bermutu baik dan harga tinggi. Harapannya, petani dengan menggunakan biaya produksi secara seefisien, maka pendapatan bersih usahatani dapat meningkat.

Menurut Soekatawi

(1995), pendapatan bersih usahatani diperoleh dari selisih antara penerimaan usahatani dan pengeluaran tunai usahatani. Penerimaan usahatani dipengaruhi oleh harga dan jumlah produk yang terjual. Harga jual jambu biji varietas getas merah pada saat musim hujan menurun drastis menjadi Rp 2.500 hingga $\mathrm{Rp}$ 3.000. Hal ini dikarenakan terjadinya panen raya di sejumlah wilayah sentra produksi jambu biji varietas getas merah pada waktu yang bersamaan. Kondisi tersebut menyebabkan jumlah produksi jambu biji varietas getas merah Desa Panyingkiran banyak dan dijual dengan harga murah sehingga petani memperoleh pendapatan yang rendah.

\section{METODE PENELITIAN}

Lokasi penelitian berada di Desa Panyingkiran, Kecamatan Panyingkiran, Kabupaten Majalengka, Provinsi Jawa Barat. Desain penelitian yang digunakan dalam penelitian ini yaitu penelitian 
kualitatif. Sedangkan metode penelitian yang digunakan adalah metode survei.

Adapun variabel-variabel yang dipergunakan dalam penelitian ini yaitu:

1. Jumlah produksi adalah besar hasil usahatani jambu biji varietas getas merah dalam suatu periode diukur dalam satuan kilogram (Kg).

2. Harga jual adalah nilai uang yang harus dibayarkan oleh konsumen kepada petani atas dasar produk usahatani yang dibelinya dalam satuan rupiah per kilogram $(\mathrm{Rp} / \mathrm{Kg})$.

3. Biaya tetap adalah biaya yang tidak tergantung pada besar kecilnya produksi yang diperoleh, meliputi sewa lahan, biaya pajak, dan biaya penyusutan (Rp).

4. Biaya variabel adalah biaya yang digunakan untuk memperoleh faktor produksi meliputi penggunaan bibit, pupuk, pestisida, pembungkus, dan tenaga kerja (Rp).

5. Biaya produksi adalah keseluruhan biaya yang dikeluarkan dalam proses produksi yakni penjumlahan antara biaya tetap dan biaya variabel yang diukur dalam satuan rupiah ( $R p)$.

6. Penerimaan usahatani adalah nilai produksi yang diperoleh dari perkalian antara produk total dengan harga jual ditingkat petani yang diukur dalam satuan rupiah (Rp).

7. Pendapatan usahatani adalah hasil selisih antara penerimaan yang diperoleh petani dengan biaya yang dikeluarkan petani dalam proses usahatani yang diukur dalam satuan rupiah $(\mathrm{Rp})$.

8. Imbangan perbandingan antara penerimaan yang diperoleh petani dan biaya yang dikeluarkan petani dalam proses usahatani $(\mathrm{R} / \mathrm{C})$.

Populasi dalam penelitian ini adalah seluruh petani jambu biji merah di Desa Panyingkiran Kecamatan Panyingkiran Kabupaten Majalengka dengan jumlah populasi 103 terdiri atas 3 petani menggunakan SOP dan 100 orang petani Non SOP. Pengambilan sampel petani yang menggunakan SOP yaitu dengan teknik sampel jenuh (sensus), 3 petani tersebut diambil semuanya sebagai sampel. Sedangkan, pengambilan sampel petani yang Non SOP didasarkan pada rumus slovin dengan jumlah populasi dan toleransi kesalahan $(\alpha)$ 10\%. Sehingga didapatkan jumlah sampel yaitu 50 petani. Strata yang digunakan dalam penelitian ini berdasarkan luas lahan tanaman jambu biji varietas getas merah. Diadaptasi dari Anderson, et al (2011), perhitungan tersebut didapatkan rentang 
interval 0,22 ha untuk setiap strata. Pengambilan sampel dalam populasi petani yang Non SOP yaitu dengan teknik disproportionate stratified random sampling. Mengenai jumlah sampel petani Non SOP dapat dilihat pada Tabel 1.

Tabel 1. Perhitungan Jumlah Sampel

\begin{tabular}{clcc}
\hline No. & Strata & $\begin{array}{l}\text { Pupulasi } \\
\text { (orang) }\end{array}$ & $\begin{array}{c}\text { Sampel } \\
\text { (orang) }\end{array}$ \\
\hline 1. & $\begin{array}{l}\text { Lahan sempit } \\
(0,04 \text { ha }-0,26\end{array}$ & 94 & 44 \\
ha) & 4 & 4 \\
2. & $\begin{array}{l}\text { Lahan sedang } \\
(0,27 \text { ha }-0,49\end{array}$ \\
ha) & $\begin{array}{l}\text { Lahan luas }(0,5 \\
\text { ha }-0,72 \text { ha) }\end{array}$ & 2 & 2 \\
\hline & 100 & 50 \\
\hline
\end{tabular}

Teknik pengumpulan data yang digunakan yaitu wawancara, observasi, kuesioner dan studi pustaka. Dalam penelitian ini, wawancara yang dilakukan adalah secara terstruktur dimana dalam proses wawancara telah disiapkan pertanyaan pertanyaan tertulis yang alternatif jawabannya telah disiapkan. Observasi dalam penelitian ini peneliti melakukan pengamatan langsung terhadap objek penelitian di lapangan. Kuesioner dalam penelitian ini yaitu melalui pertanyaan berdasarkan operasionalisasi variabel. Studi pustaka dalam penelitian ini adalah teori teori yang berasal dari jurnal, buku, skripsi, Badan Pusat Statistik, Dinas Pertanian
Kabupaten Majalengka, dan media informasi lainya yang berkaitan dengan penelitian.

\section{Analisis Biaya Usahatani}

Menurut Soekartawi (1995), biaya produksi atau biaya usahatani yaitu semua pengeluaran yang dipergunakan dalam suatu usahatani atau produksi. Biaya usahatani diklasifikasikan menjadi dua, antara lain:

a. Biaya tetap (Fixed Cost) ialah biaya yang relatif tetap jumlahnya dan terus dikeluarkan walaupun produksi yang diperoleh banyak atau sedikit. Cara menghitung biaya tetap yaitu:

$$
\mathrm{FC}=\sum \mathrm{X} . \mathrm{PX}
$$

Keterangan:

$\mathrm{FC}=$ Biaya tetap $(\mathrm{Rp})$

$\mathrm{X}=$ Jumlah fisik dari input yang membentuk biaya tetap

$\mathrm{Px}=$ Harga input $(\mathrm{Rp})$

Penyusutan alat termasuk dalam biaya diperhitungkan yang dihitung dengan metode garis lurus (straight line method) yaitu setiap tahun biaya penyusutan yang dikeluarkan relatif sama. Rumus yang digunakan yaitu:

$\mathrm{Dp}=(\mathrm{c}-\mathrm{s}) / \mathrm{n}$

Keterangan :

$\mathrm{Dp}=$ Penyusutan $/$ tahun

$\mathrm{c}=$ Nilai beli

$\mathrm{s}=$ Nilai sisa 
$\mathrm{n}=$ Umur pemakaian barang

b. Biaya tidak tetap atau biaya variabel (Variable Cost) ialah biaya yang besar kecilnya dipengaruhi oleh produksi yang diperoleh. Cara menghitung biaya variabel yaitu:

$\mathrm{VC}=\sum \mathrm{X} . \mathrm{Px}$

Keterangan :

$\mathrm{FC}=$ Biaya tetap $(\mathrm{Rp})$

$\mathrm{X}=$ Jumlah fisik dari input yang membentuk biaya variabel

$P x=$ Harga input $(R p)$

Total biaya produksi adalah penjumlahan dari biaya tetap (Fixed Cost) dan biaya variabel (Variabel Cost). Rumus mengitung total biaya produksi yaitu:

$\mathrm{TC}=\mathrm{TFC}+\mathrm{TVC}$

Keterangan:

$\mathrm{TC}=$ Total pengeluaran ( $\mathrm{Rp})$

$\mathrm{TFC}=$ Total biaya tetap $(\mathrm{Rp})$

$\mathrm{TVC}=$ Total biaya variabel $(\mathrm{Rp})$

\section{Analisis Penerimaan Usahatani}

Menurut Soekartawi

(1995),

penerimaan usahatani adalah perkalian antara produksi yang diperoleh dari harga jual. Rumus penerimaan usahatani ditulis sebagai berikut:

$\mathrm{TR}=\mathrm{Y} . \mathrm{Py}$

Keterangan:

$\mathrm{TR}=$ Total penerimaan $(\mathrm{Rp})$
$\mathrm{Y}=$ Jumlah produksi yang diperoleh dalam suatu usahatani

Py $=$ Harga Produksi (Rp)

\section{Analisis Pendapatan Usahatani}

Pendapatan usahatani diperoleh dari selisih antara penerimaan usahatani dan pengeluaran usahatani (Soekartawi, 1984). Berikut ini adalah rumus untuk mencari pendapatan usahatani yaitu:

$$
\mathrm{Pd}=\mathrm{TR}-\mathrm{TC}
$$

Keterangan:

$\mathrm{Pd}=$ Pendapatan usahatani $(\mathrm{Rp})$

$\mathrm{TR}=$ Total penerimaan $(\mathrm{Rp})$

$\mathrm{TC}=$ Total biaya $(\mathrm{Rp})$

Analisis Imbangan Penerimaan (R) dan Biaya (C)

R/C adalah singkatan dari Return Cost Ratio, atau dikenal sebagai perbandingan (nisbah) antara penerimaan dan biaya (Soekartawi, 1995). Rumus analisis $\mathrm{R} / \mathrm{C}$ ialah sebagai berikut:

$\mathrm{A}=\mathrm{R} / \mathrm{C}$

$\mathrm{R}=\mathrm{Py} . \mathrm{Y}$

$\mathrm{C}=\mathrm{FC}+\mathrm{VC}$

$\mathrm{A}=\{(\mathrm{Py} . \mathrm{Y}) /(\mathrm{FC}+\mathrm{VC})\}$

Keterangan :

$\mathrm{R}=$ Penerimaan

$\mathrm{C}$ = Biaya

Py = Harga output

$\mathrm{Y}=$ Output

FC = Biaya tetap (Fixed Cost)

$\mathrm{VC}=$ Biaya variabel (Variabel Cost) 
Berikut ini adalah kriteria untuk mengetahui keuntungan pada suatu usahatani:

1. Apabila $R / C<1$ maka usahatani yang dilakukan secara ekonomi belum menguntungkan

2. Apabila $R / C=1$ maka usahatani yang dilakukan secara ekonomi berada pada titik impas (Break Even Point)

3. Apabila $R / C>1$ maka usahatani yang dilakukan secara ekonomi menguntungkan

\section{HASIL DAN PEMBAHASAN}

\section{Karakteristik Responden}

Berdasarkan kelompok umur, seluruh petani SOP berada pada kelompok umur usia produktif yaitu 5064 tahun, sedangkan petani Non SOP didominasi kelompok umur sangat produktif yaitu 34-49 tahun. Berdasarkan tingkat pendidikan, petani SOP dan sebagian besar petani Non SOP merupakan lulusan SD. Berdasarkan pekerjaan, seluruh petani SOP dan sebagian besar petani Non SOP memilih mengusahakan usahatani jambu biji merah sebagai mata pencaharian utama. Berdasarkan pengalaman, sebagian besar petani SOP sudah pengalaman dalam berusahatani selama 11-20 tahun, sedangkan sebagian besar petani Non
SOP memiliki pengalaman usahatani 110 tahun. Berdasarkan status kepemilikan lahan, seluruh petani SOP dan sebagian besar petani Non SOP mengusahakan lahan miliknya sendiri. Berdasarkan kepemilikan luas lahan, seluruh petani yang menggunakan SOP dan sebagian besar petani Non SOP mengusahakan lahan miliknya sendiri. Berdasarkan jumlah pohon, bahwa petani SOP memiliki jumlah pohon lebih sedikit dibanding Non SOP. Berdasarkan luas lahan sebagian besar petani SOP dan petani Non SOP berlahan sempit $(<0,27$ $\mathrm{Ha})$.

\section{Analisis Pendapatan Usahatani}

\section{Biaya Total Produksi}

Berikut ini adalah tabel biaya total produksi jambu biji varietas getas merah berdasarkan luas lahan garapan.

Dapat dilihat pada Tabel 2. rata-rata total biaya produksi tertinggi di Desa Panyingkiran dimiliki oleh petani SOP berlahan garapan sempit yaitu $R p$ 137.333.701/ha/tahun. Demikian halnya, petani Non SOP berlahan garapan sempit memiliki rata-rata total biaya produksi yang lebih tinggi yaitu Rp 121.498.322/Ha/tahun. Hal ini dikarenakan petani yang mengusahakan lahan yang sempit lebih intensif memelihara usahataninya sehingga biaya produksi yang dikeluarkan menjadi lebih besar. Berdasarkan hasil wawancara, 
hampir sebagian besar petani yang memiliki luas lahan garapan yang sempit beranggapan bahwa semakin besar biaya produksi yang dikeluarkan maka hasil produksi pun akan ikut meningkat.

Tabel 2. Rata Rata Biaya Produksi Jambu Biji Varietas Getas Merah Berdasarkan Lahan Garapan (Rp/ha/tahun)

\begin{tabular}{lrrrrrr}
\hline \multirow{2}{*}{ Biaya } & \multicolumn{2}{c}{ SOP (Rp/ha/tahun) } & \multicolumn{2}{c}{ Non SOP (Rp/ha/tahun) } \\
\cline { 2 - 7 } & \multicolumn{1}{c}{$\begin{array}{c}\text { Lahan } \\
\text { Sempit }\end{array}$} & $\begin{array}{c}\text { Lahan } \\
\text { Sedang }\end{array}$ & $\begin{array}{c}\text { Lahan } \\
\text { Luas }\end{array}$ & \multicolumn{1}{c}{$\begin{array}{c}\text { Lahan } \\
\text { Sempit }\end{array}$} & \multicolumn{1}{c}{$\begin{array}{c}\text { Lahan } \\
\text { Sedang }\end{array}$} & \multicolumn{1}{c}{$\begin{array}{c}\text { Lahan } \\
\text { Luas }\end{array}$} \\
\hline Biaya Tetap & 2.892 .262 & & 1.120 .000 & 7.534 .346 & 5.077 .917 & 940.289 \\
Biaya Variabel & 24.838 .095 & & 9.640 .000 & 25.553 .991 & 23.252 .143 & 15.265 .952 \\
Biaya Tunai & 27.730 .357 & - & 10.760 .000 & 33.088 .338 & 28.330 .060 & 16.206 .241 \\
Biaya Tetap & 3.922 .391 & & 1.771 .875 & 2.888 .426 & 4.155 .157 & 1.276 .529 \\
Biaya Variabel & 105.680 .952 & & 6.120 .000 & 85.521 .558 & 32.364 .286 & 19.538 .095 \\
Biaya Diperhitungkan & 109.603 .343 & - & 7.891 .875 & 88.409 .984 & 36.519 .443 & 20.814 .624 \\
Total Biaya Produksi & 137.333 .701 & & 18.651 .875 & 121.498 .322 & 64.849 .502 & 37.020 .865 \\
\hline
\end{tabular}

\section{Penerimaan Usahatani}

Menurut Soekartawi (1995), penerimaan usahatani adalah perkalian antara hasil produksi yang diperoleh petani dengan harga jual. Penerimaan usahatani jambu biji varietas getas merah di Desa Panyingkiran didapatkan dari penjumlahan penerimaan usahatani selama tiga periode musim panen (panen besar, panen sedang, panen kecil). Penerimaan usahatani pada setiap periode panen bergantung pada hasil produksi dan harga yang ada. Jumlah produksi dan harga jambu biji varietas getas merah di Desa Panyingkiran berfluktuatif, namun jumlah produksi tertinggi pada umumnya terjadi pada periode panen besar (Maret hingga Mei). Penerimaan usahatani jambu biji varietas di Desa Panyingkiran berdasarkan kepemilikan lahan tersaji pada Tabel 3.

Tabel 3. Rata-Rata Penerimaan Usahatani Jambu Biji Varietas Getas Merah berdasarkan Lahan Garapan (Rp/Hektar/Tahun)

\begin{tabular}{|c|c|c|c|c|c|c|}
\hline \multirow[b]{2}{*}{ Panen } & \multicolumn{3}{|c|}{ SOP (Rp/ha/tahun) } & \multicolumn{3}{|c|}{ Non SOP (Rp/ha/tahun) } \\
\hline & $\begin{array}{l}\text { Lahan } \\
\text { Sempit }\end{array}$ & $\begin{array}{c}\text { Lahan } \\
\text { Sedang }\end{array}$ & $\begin{array}{c}\text { Lahan } \\
\text { Luas }\end{array}$ & $\begin{array}{c}\text { Lahan } \\
\text { Sempit }\end{array}$ & $\begin{array}{c}\text { Lahan } \\
\text { Sedang }\end{array}$ & $\begin{array}{c}\text { Lahan } \\
\text { Luas }\end{array}$ \\
\hline Besar & 134.659 .036 & & 94.057 .143 & 59.203 .943 & 69.860 .090 & 24.979 .767 \\
\hline Sedang & 69.608 .672 & & 56.424 .490 & 35.416 .799 & 41.865 .888 & 14.976 .740 \\
\hline Kecil & 33.268 .571 & & 33.600 .000 & 27.027 .532 & 17.462 .857 & 11.337 .143 \\
\hline Total & 237.536 .280 & & 184.081 .633 & 121.648 .274 & 129.188 .835 & 51.293 .650 \\
\hline
\end{tabular}

Dapat dilihat pada Tabel 3. petani $S O P$ yang memiliki rata-rata penerimaan usahatani tertinggi didapatkan oleh petani yang lahannya sempit yaitu $\mathrm{Rp}$ 237.536.280/Ha/tahun. Berbeda halnya dengan petani Non SOP, rata-rata penerimaan usahatani tertinggi didapatkan oleh petani berlahan garapan sedang yaitu $\mathrm{Rp}$ 129.188.835/Ha/tahun. Hal ini dikarenakan petani $S O P$ berlahan garapan sempit dan petani Non SOP berlahan garapan sedang mendapatkan rata-rata harga jual dan jumlah produksi yang lebih tinggi sehingga 
mempengaruhi penerimaan yang menjadi tinggi.

\section{Pendapatan Usahatani}

Dalam penelitian ini, pendapatan usahatani jambu biji variatas getas merah diperoleh dari tiga periode panen dalam satu tahun. Analisis pendapatan usahatani penting untuk diketahui karena dapat memberikan gambaran mengenai keuntungan dari kegiatan usahatani yang telah dilakukan. Tabel 4 adalah pendapatan usahatani jambu biji varietas getas merah di Desa Panyingkiran.

Tabel 4. Rata-rata Pendapatan Usahatani Jambu Biji Varietas Getas Merah berdasarkan Luas Lahan Garapan (Rp/ha/tahun)

\begin{tabular}{|c|c|c|c|c|c|c|}
\hline \multirow[b]{2}{*}{ Uraian } & \multicolumn{3}{|c|}{ SOP (Rp/ha/tahun) } & \multicolumn{3}{|c|}{ Non SOP (Rp/ha/tahun) } \\
\hline & $\begin{array}{l}\text { Lahan } \\
\text { Sempit }\end{array}$ & $\begin{array}{c}\text { Lahan } \\
\text { Sedang }\end{array}$ & Lahan Luas & $\begin{array}{l}\text { Lahan } \\
\text { Sempit }\end{array}$ & $\begin{array}{l}\text { Lahan } \\
\text { Sedang }\end{array}$ & $\begin{array}{c}\text { Lahan } \\
\text { Luas }\end{array}$ \\
\hline Biaya Tunai & 27.730 .357 & - & 10.760 .000 & 33.088 .338 & 28.330 .060 & 16.206 .241 \\
\hline Biaya Total Produksi & 137.333 .701 & & 18.651 .875 & 121.498 .322 & 64.849 .502 & 37.020 .865 \\
\hline Penerimaan & 237.536 .280 & - & 184.081 .633 & 121.648 .274 & 129.188 .835 & 51.293 .650 \\
\hline $\begin{array}{l}\text { Pendapatan atas } \\
\text { Biaya Tunai }\end{array}$ & 209.805 .922 & & 173.321 .633 & 88.559 .936 & 100.858 .775 & 35.087 .409 \\
\hline $\begin{array}{l}\text { Pendapatan atas } \\
\text { Biaya Total }\end{array}$ & 100.202 .579 & & 165.429 .758 & 149.952 & 64.339 .333 & 14.272 .785 \\
\hline
\end{tabular}

Tabel 4. rata-rata pendapatan atas biaya tunai tertinggi didapatkan oleh petani SOP berlahan garapan sempit yaitu $\mathrm{Rp}$ 209.805.922/Ha/tahun dan petani Non SOP berlahan garapan sedang yaitu $R p$ 100.858.775/ha/tahun. Disamping itu, ratarata pendapatan atas biaya total tertinggi didapatkan oleh petani SOP yang berlahan garapan luas yaitu $\mathrm{Rp}$ 165.429.758/ha/tahun dan petani Non SOP berlahan garapan sedang yaitu Rp 64.339.333/ha/Tahun. Hal ini dikarenakan petani SOP pada lahan garapan luas dan petani Non SOP berlahan garapan sedang memiliki rata-rata total biaya diperhitungkan lebih rendah dibandingkan petani SOP berlahan garapan sempit dan petani Non SOP berlahan garapan sempit, sehingga nilai tersebut mempengaruhi pendapatan atas biaya total. Secara keseluruhan, petani SOP memperoleh keuntungan yang lebih besar dari pada petani Non SOP. Hal tersebut dikarenakan petani SOP mengeluarkan biaya produksi yang lebih sedikit dan mendapatkan penerimaan yang lebih besar sehingga pendapatan usahatani menjadi lebih besar dibandingkan petani Non SOP.

\section{R/C Usahatani}

Analisis imbangan penerimaan dan biaya $(R / C)$ bertujuan untuk mengetahui besar keuntungan yang diperoleh dari usaha yang dilakukan. Rata-rata $\mathrm{R} / \mathrm{C}$ dapat dilihat pada tabel berikut ini. 
MIMBAR AGRIBISNIS

Jurnal Pemikiran Masyarakat Ilmiah Berwawasan Agribisnis. Juli 2020. 6(2): 754-764

Tabel 5. R/C Usahatani Jambu Biji Varietas Getas Merah berdasarkan Luas Lahan Garapan

\begin{tabular}{lcccccc}
\hline \multirow{2}{*}{ Panen } & \multicolumn{3}{c}{ SOP $($ Rp/Ha/Tahun) } & \multicolumn{2}{c}{ Non SOP (Rp/Ha/Tahun) } \\
\cline { 2 - 7 } & $\begin{array}{c}\text { Lahan } \\
\text { Sempit }\end{array}$ & $\begin{array}{c}\text { Lahan } \\
\text { Sedang }\end{array}$ & $\begin{array}{c}\text { Lahan } \\
\text { Luas }\end{array}$ & $\begin{array}{c}\text { Lahan } \\
\text { Sempit }\end{array}$ & $\begin{array}{c}\text { Lahan } \\
\text { Sedang }\end{array}$ & $\begin{array}{c}\text { Lahan } \\
\text { Luas }\end{array}$ \\
\hline R/C atas biaya tunai & 8,5659 & - & 17,1080 & 3,6765 & 4,5601 & 3,1651 \\
R/C atas biaya total & 1,7296 & - & 9,8693 & 1,0012 & 1,9921 & 1,3855 \\
\hline
\end{tabular}

Tabel 5. menunjukkan bahwa, petani SOP berlahan garapan luas memiliki $\mathrm{R} / \mathrm{C}$ atas biaya tunai tertinggi yaitu 17,1 artinya bahwa setiap pengeluaran $\mathrm{Rp} 1$ maka akan menghasilkan penerimaan $\mathrm{Rp} 17,1$ dan pendapatan Rp 16,1. Selain itu, petani Non SOP berlahan garapan sedang memiliki $\mathrm{R} / \mathrm{C}$ atas biaya tunai tertinggi yaitu 4,6 artinya bahwa setiap pengeluaran Rp 1 maka akan menghasilkan penerimaan $\mathrm{Rp}$ 4,6 dan pendapatan Rp 3,6. Demikian halnya dengan $\mathrm{R} / \mathrm{C}$ atas biaya total tertinggi didapatkan oleh petani SOP berlahan garapan luas yaitu 9,9 artinya bahwa setiap pengeluaran Rp 1 maka akan menghasilkan penerimaan $\mathrm{Rp}$ 9,9 dan pendapatan $\mathrm{Rp} 8,9$. Selain itu, $\mathrm{R} / \mathrm{C}$ atas biaya total tertinggi didapatkan petani Non SOP berlahan garapan sedang yaitu 2,0 artinya bahwa setiap pengeluaran Rp 1 maka akan menghasilkan penerimaan $\mathrm{Rp} 2,0$ dan pendapatan Rp 1,0. Dapat disimpulkan, baik petani SOP maupun Non SOP secara ekonomi lebih menguntungkan, hal ini dikarenakan nilai $\mathrm{R} / \mathrm{C}$ adalah lebih dari satu.

\section{KESIMPULAN DAN SARAN}

\section{Kesimpulan}

1. Rata-rata total biaya produksi tertinggi di Desa Panyingkiran terdapat pada petani SOP berlahan garapan sempit yaitu Rp 137.333.701/ha/tahun dan petani Non SOP berlahan garapan sempit yaitu $\mathrm{Rp}$ 121.498.322/ha/tahun.

2. Rata-rata penerimaan usahatani tertinggi di Desa Panyingkiran terdapat pada petani SOP yang berlahan garapan sempit yaitu Rp 237.536.280/ha/tahun dan petani Non SOP yang berlahan garapan sedang yaitu Rp 129.188.835/ha/tahun.

3. Rata-rata pendapatan usahatani di Desa Panyingkiran, Kecamatan Panyingkiran, Kabupaten Majalengka secara umum menguntungkan. Rata-rata pendapatan atas biaya tunai tertinggi didapatkan oleh petani SOP berlahan garapan sempit yaitu Rp 209.805.922/ha/tahun dan petani Non SOP berlahan garapan sedang yaitu Rp 100.858.775/ha/tahun. Disamping itu, rata-rata pendapatan atas biaya total tertinggi didapatkan oleh petani SOP yang berlahan garapan luas yaitu $\mathrm{Rp}$ 165.429.758/ha/tahun dan petani Non SOP berlahan garapan sedang yaitu $\mathrm{Rp}$ 64.339.333/ha/Tahun.Nilai imbangan penerimaan dengan biaya $(\mathrm{R} / \mathrm{C})$ petani jambu biji varietas getas merah di Desa Panyingkiran, Kecamatan Panyingkiran, Kabupaten Majalengka adalah lebih besar dari 1 yang menunjukkan bahwa 


\section{ANALISIS PENDAPATAN USAHATANI JAMBU BIJI VARIETAS GETAS MERAH DI DESA \\ PANYINGKIRAN, KECAMATAN PANYINGKIRAN, KABUPATEN MAJALENGKA \\ Nadyla Rizka Nur Amelia, Dini Rochdiani, Bobby Rachmat Saefudin}

usahatani jambu biji varietas getas merah secara ekonomi menguntungkan. Nilai $\mathrm{R} / \mathrm{C}$ atas biaya tunai tertinggi terdapat pada petani SOP berlahan garapan luas $(\mathrm{R} / \mathrm{C}=17,1)$ dan pada petani Non SOP terdapat pada petani berlahan garapan sedang $(\mathrm{R} / \mathrm{C}=4,6)$. Sedangkan, nilai $\mathrm{R} / \mathrm{C}$ atas biaya total tertinggi terdapat pada petani SOP berlahan garapan luas $(\mathrm{R} / \mathrm{C}=9,9)$ dan pada petani Non SOP terdapat pada petani berlahan garapan sedang $(R / C=2,0)$.

\section{Saran}

1. Perlu adanya kegiatan pengembangan usahatani jambu biji varietas getas merah sehingga dapat meningkatkan pendapatan usahatani petani, salah satunya dengan cara melakukan kegiatan yang berkaitan dengan peningkatan nilai tambah jambu biji varietas getas merah seperti membuat olahan makanan dan minuman. Sebaiknya dinas setempat dapat memfasilitasi pemberian mesin pengolahan seperti mesin pembuat puree jambu biji varietas getas merah untuk Desa Panyingkiran, sehingga masyarakat menjadi termotivasi untuk meningkatkan kegiatan perekonomian dan membuka lapangan pekerjaan.

2. Agar pelaksanaan SOP dapat berjalan secara efektif, maka pemerintah dalam hal ini instansi terkait harus memberikan buku pedoman SOP kepada para petani dan mengagendakan kegiatan diskusi mengenai SOP serta dalam pelaksanannya harus ada pengawasan dan pendampingan secara intensif.

3. Budidaya jambu biji varietas getas merah sebaiknya dilakukan dengan cara menerapkan petunjuk teknis yang ada di buku pedoman SOP Jambu Biji Merah, melakukan budidaya pada kondisi lahan garapan yang luas, serta tetap melakukan efesiensi biaya produksi. Dengan demikian, pendapatan usahatani petani jambu biji varietas getas merah dapat meningkat

\section{DAFTAR PUSTAKA}

Anderson, et al . (2011). Statistic For Business and Economics Iie. USA. MPS Limited.

Badan Pusat Statistik. (2019). Produksi Buah Buahan Alpukat Jeruk Besar Durian dan Jambu Biji menurut Kabupaten Kota di Provinsi Jawa Barat. BPS. Jawa Barat.

Badan Pusat Statistik. (2019). Produksi Jambu Biji di Kabupaten Majalengka. BPS. Majalengka.

Buku Pertanian Desa Panyingkiran. (2019). Produksi Jambu Biji Getas Merah Tahun 2014-2018 di Desa Panyingkiran. Majalengka. Desa Panyingkiran.

Rasmikayati, E., L. Sulistyowati, dan B. R. Saefudin. (2017). Risiko Produksi dan Pemasaran Terhadap Pendapatan Petani Mangga: Kelompok Mana yang Paling Berisiko. Mimbar Agribisnis: Jurnal Pemikiran Masyarakat Ilmiah Berwawasan Agribisnis. 3(2): 105-116.

Amir, N. H., E. Rasmikayati, B. R. Saefudin. (2017). Analisis 
Usahatani Kopi di Kelompok Tani Hutan Giri Senang Desa Giri Mekar Kabupaten Bandung. Jurnal Ilmiah Mahasiswa Agroinfo Galuh. 4(3): 472-479.
Soekartawi. et al. (1984). Ilmu Usahatani dan Penelitian untuk Pengembangan Petani Kecil. Jakarta. Universitas Indonesia.

Soekartawi. (1995). Analisis Usahatani. Jakarta: Universitas Indonesia. 